\title{
Bilateral Facial Palsy: A Clinical Approach
}

\author{
Alvin Yang ${ }^{1}$, Vikram Dalal ${ }^{1}$ \\ 1. Family Medicine, Schulich School of Medicine \& Dentistry, Western University, London, CAN
}

Corresponding author: Alvin Yang, alvinyang@live.ca

\begin{abstract}
Bilateral facial palsy (BFP) is exceedingly rare, representing only $0.3 \%-2.0 \%$ of facial palsy cases. Unlike unilateral facial palsy, it is often caused by a serious underlying systemic disease and therefore warrants urgent medical intervention. The differential diagnosis is broad, and detailed history, physical examination, and investigations are essential for identifying the etiology. Common acquired causes in existing case series include Lyme disease, Guillain-Barré syndrome, sarcoidosis, trauma, and Bell’s palsy. Palsy that develops rapidly is often caused by trauma, infections, or autoimmune disorders, whereas slow progressive palsy suggests neoplastic diseases. While management varies by etiology, the physician can consider early empiric corticosteroids given their efficacy in numerous differential diagnoses. Antivirals can be considered in those with a strong history of viral prodrome. In this paper, we present the case of a puerperal patient with BFP and discuss its differential diagnosis, diagnostic approach, and management.
\end{abstract}

Categories: Emergency Medicine, Family/General Practice, Neurology

Keywords: pregnancy, puerperal, bell's palsy, lyme's disease, bilateral, facial, palsy, paralysis, guillain-barre syndrome (gbs), sarcoidosis

\section{Introduction}

Unilateral facial palsy is relatively common with an incidence of 20-25 per 100,000 population, where the majority of cases (>50\%) are attributed to Bell's (i.e. idiopathic) palsy (BP) $[1,2]$. In comparison, bilateral facial palsy (BFP) is exceedingly rare, representing only $0.3 \%-2.0 \%$ of facial palsy cases [3,4]. BFP is often a finding of a serious systemic disease, with BP seldom being the cause $(<20 \%)[2,3,5]$. Many of these diseases are potentially life-threatening and therefore warrant urgent medical intervention [1]. In this paper, we present the case of a puerperal patient with BFP and discuss its differential diagnosis, diagnostic approach, and management.

\section{Case Presentation}

A 31-year-old Caucasian female presented to the emergency department (ED) with BFP. She had delivered her daughter seven days prior and noticed hypogeusia the same day. She subsequently developed left-sided facial weakness on day 4 and right-sided facial weakness on day 7. She denied diplopia, facial numbness, otological symptoms, dysphagia, as well as jaw and neck weakness. She had no sensory changes, pain, or weakness in the body. There were no bladder or bowel symptoms, nor head or neck trauma. She had no recent infectious symptoms, sick contacts, or travel. There was no history of facial palsy. Of note, she had received a rubella vaccine two days after the delivery of her child.

On examination, the patient had stable vital signs and was in no apparent distress. Her facial strength was decreased bilaterally with an inability to elevate eyebrows, puff out cheeks, or smile. Two millimeters of inferior scleral margins remained visible bilaterally, indicating inadequate closure of both eyelids. There was no fatiguability. The remainder of the cranial nerve examinations were normal. She had intact sensation, strength, tone, and reflexes in bilateral upper and lower extremities. Gait was normal and plantar response was down-going. There were no rashes.

Initial blood work demonstrated complete blood count (CBC) to be within normal range. Similarly, serum glucose, sodium, potassium, chloride, bicarbonate, magnesium, calcium, and phosphate were also within normal range. C-reactive protein (CRP) was very minimally elevated at $15.2 \mathrm{mg} / \mathrm{L}$.

Our patient was referred to and assessed by the Urgent Neurology Clinic within hours of presenting to the ED. Interestingly, further investigations were not performed, possibly due to her relatively benign history and exam, lack of red flags, and puerperal association. She was clinically diagnosed with bilateral BP and discharged home with eye patching only. Follow-up at eight weeks later revealed a complete resolution of the BFP without any additional symptoms. Therefore, a final diagnosis of bilateral BP in puerperium was established and the patient was discharged without further investigations or follow-up. While a more extensive workup was not performed, this case nonetheless promotes discussion on additional management considerations. 


\section{Cureus}

\section{Discussion}

\section{Differential diagnosis}

Tables 1,2 show compiled etiologies from previous literature, including BFP during puerperium [1,2,6-9].

\begin{tabular}{|c|c|c|}
\hline Viral & Bacterial & Spirochete, protozoa, fungi \\
\hline Arbovirus & Diphtheria & Borreliosis (Lyme disease) \\
\hline Brainstem encephalitis & Intracranial abscess (mycoplasma pneumoniae) & Leptospirosis \\
\hline Coxsakie virus & Leprosy & Malaria \\
\hline CMV & Meningitis & Syphilis \\
\hline EBV & Otitis media (bilateral) & Cryptococcal meningitis \\
\hline GBS (Miller Fisher syndrome) & Scarlet fever & \\
\hline HIV & Tetanus & \\
\hline HTLV-1 & Tuberculosis & \\
\hline \multicolumn{3}{|l|}{ HZV (Ramsay Hunt syndrome) } \\
\hline \multicolumn{3}{|l|}{ Influenza } \\
\hline Mumps & & \\
\hline
\end{tabular}

\section{TABLE 1: Infectious etiologies of bilateral facial palsy}

CMV, cytomegalovirus; EBV, Epstein-Barr virus; GBS, Guillain-Barré syndrome; HIV, human immunodeficiency virus; HTLV-1, human T-lymphotropic virus; $\mathrm{HZV}$, herpes zoster virus. 


\section{Cureus}

\begin{tabular}{|c|c|c|c|c|c|c|c|c|}
\hline Autoimmune & Congenital & Metabolic & Neoplastic & Neurological/Neuromuscular & Traumatic & Vascular & latrogenic & Idiopathic \\
\hline Amyloidosis & $\begin{array}{l}\text { Facial } \\
\text { musculature } \\
\text { absence }\end{array}$ & $\begin{array}{l}\text { Acute } \\
\text { porphyria }\end{array}$ & $\begin{array}{l}\text { Acoustic } \\
\text { neuroma }\end{array}$ & $\begin{array}{l}\text { Benign intracranial } \\
\text { hypertension }\end{array}$ & $\begin{array}{l}\text { Facial } \\
\text { injury/laceration }\end{array}$ & $\begin{array}{l}\text { Brainstem } \\
\text { cavernous } \\
\text { hemangioma }\end{array}$ & $\begin{array}{l}\text { Arterial } \\
\text { embolization }\end{array}$ & $\begin{array}{l}\text { Bell's } \\
\text { palsy }\end{array}$ \\
\hline Sarcoidosis & $\begin{array}{l}\text { Myotonic } \\
\text { dystrophy }\end{array}$ & $\begin{array}{l}\text { Diabetes } \\
\text { mellitus }\end{array}$ & Cholesteatoma & Vestibular schwannomas & $\begin{array}{l}\text { Forceps birth } \\
\text { trauma }\end{array}$ & $\begin{array}{l}\text { Polyarteritis } \\
\text { nodosa }\end{array}$ & $\begin{array}{l}\text { Rabies } \\
\text { antiserum } \\
\text { inoculation }\end{array}$ & \\
\hline SJS & $\begin{array}{l}\text { Melkersson- } \\
\text { Rosenthal } \\
\text { syndrome }\end{array}$ & $\begin{array}{l}\text { Wernicke- } \\
\text { Korsakoff } \\
\text { syndrome }\end{array}$ & Ependymoma & Jlbospinal neuropathy & Parotid surgery & Pregnancy & Vaccine & \\
\hline \multirow[t]{5}{*}{ SLE } & $\begin{array}{l}\text { Moebius } \\
\text { syndrome }\end{array}$ & & Leukemia & Multiple sclerosis & $\begin{array}{l}\text { Skull base } \\
\text { fracture }\end{array}$ & Puerperium & & \\
\hline & Sclerosteosis & & Lymphoma & Myasthenia gravis & & $\begin{array}{l}\text { Temporal } \\
\text { arteritis }\end{array}$ & & \\
\hline & $\begin{array}{l}\text { Thalidomide } \\
\text { embryopathy }\end{array}$ & & Pontine glioma & Parkinson's disease & & & & \\
\hline & & & $\begin{array}{l}\text { Von } \\
\text { Recklinghausen's } \\
\text { disease }\end{array}$ & seudobulbar/bulbar palsy & & & & \\
\hline & & & & ic astroc & & & & \\
\hline
\end{tabular}

TABLE 2: Non-infectious etiologies of bilateral facial palsy

SJS, Stevens-Johnson syndrome; SLE, Systemic lupus erythematosus.

The most common acquired etiologies reported across case series were Lyme disease, Guillain-Barré syndrome (GBS), sarcoidosis, trauma, and BP [1,6,9,10]. Palsy that develops rapidly is often caused by trauma, infections, or autoimmune disorders. Slow progressive palsy suggests neoplastic diseases. Synchronous palsy with involvement of the contralateral side within 30 days may represent systemic diseases whereas synchronous palsy with involvement of the contralateral side after 30 days may represent more localized inflammatory conditions [6].

\section{Diagnostic approach}

Detailed history, physical examinations, and investigations are essential for identifying the etiology. History should include symptom characterization (e.g. time sequence of onset, synchronicity, taste change), associated symptoms (e.g. diplopia, facial numbness, otological symptoms, aphasia, vesicles), relevant risk factors (e.g. viral prodrome, camping, immunizations), and prior palsy history [2]. The physical examination should assess all systems, paying special attention to localizing neurological deficits. Classifications include unilateral vs. bilateral distribution, central vs. peripheral neuropathy, upper motor neuron vs. lower motor neuron lesion, myotome and dermatome distribution, proximal vs. distal muscle weakness, and fatiguability. Clinical syndromes can raise a high index of suspicion for specific diseases. Headache, visual disturbance, and jaw claudication suggest temporal arteritis, while headache and papilledema suggest benign intracranial hypertension. Intermittent monosymptomatic attacks compatible with demyelination (e.g. optic neuritis, painless binocular diplopia, cerebellar syndrome) may indicate multiple sclerosis. Myasthenia gravis is characterized by fluctuating skeletal muscle weakness and fatiguability, often with ocular involvement (e.g. ptosis, diplopia). Bradykinesia, resting tremor, rigidity, and postural instability are hallmarks of Parkinson's Disease. Encephalopathy, oculomotor dysfunction, and gait ataxia form the classic triad for WernickeKorsakoff syndrome.

Initial bloodwork should include a CBC, electrolytes, creatinine, and blood glucose. Additional workup should be guided by history and physical examination. Investigations for the patient with infectious symptoms may include a chest X-ray, heterophil count, fluorescent treponemal antibody test, Lyme titer, and human immunodeficiency virus screen. Focal neurological deficits (e.g. asymmetric sensorimotor hearing loss) should be followed with neuroradiology (i.e. computed tomography, magnetic response imaging) to explore intracranial pathology such as acoustic neuroma, ependymoma, pilocytic astrocytoma, and brainstem cavernous hemangioma. Non-specific systemic symptoms (e.g. fatigue, arthralgia, fever) may prompt inflammatory and autoimmune biomarkers (e.g. CRP, erythrocyte sedimentation rate, antinuclear antibodies, antineutrophil cytoplasmic antibodies, antiphospholipid antibodies) for conditions such as 
systemic lupus erythematosus, amyloidosis, and polyarteritis nodosa. Blood smear and lymph node biopsy should be considered in the patient with malaise and lymphadenopathy to investigate leukemia and lymphoma. Other adjuncts include, but are not limited to, lumbar puncture for benign intracranial hypertension and tissue biopsy for amyloidosis. Urgent Neurology consult should be initiated, especially as all these investigations may not be available in an office or ED setting. The patient without an obvious etiology should be hospitalized to rule out life-threatening diseases. Only after excluding these serious possibilities should a diagnosis of BP then be considered [2,6,7].

\section{Management}

Specific management of the diverse differential diagnoses is beyond the scope of this paper; rather, we will briefly review BFP in pregnancy and puerperium as well as select systemic diseases with increased prevalence.

There is a higher incidence of facial palsy in pregnant (45/100,000 births) vs. non-pregnant (17/100,000 births) women. It presents almost exclusively in the third trimester or postpartum period [11]. Although there are case reports of BFP in pregnancy, the incidence is unknown [12,13]. The pathophysiology is poorly understood, but proposed etiologies include cortisol-mediated immunosuppression leading to viral reactivation, fluid retention within the fallopian canal causing compressive neuropathy, a hypercoagulable state producing microthrombi or emboli that occlude vasa nervorum, hormone level changes, and hypertension $[11,14,15]$. Diagnosis involves excluding other contributory systemic diseases. Prednisone $25 \mathrm{mg}$ twice daily for 10 days, started within three days of symptom onset, is usually associated with full recovery. This is generally safe for the fetus during pregnancy and neonate during breastfeeding. Concurrent valacyclovir $1000 \mathrm{mg}$ three times daily for seven days can be considered but has less supporting evidence. Delays in management are associated with worse outcomes, including persistent palsy [14]. Neonatal outcomes were favorable regardless of treatment received [11].

Lyme disease, caused by the tick-borne Borreliella infection, is the most common infectious cause of BFP (30\%-35\% of cases) [16]. In the early localized phase, it resembles a viral syndrome and commonly produces regional lymphadenopathy as well as erythema migrans ("bull's eye rash”). Early dissemination and late disease manifest in multiple systems, including diagnoses such as carditis, arthritis, and encephalopathy. The clinical features of each stage can overlap, and patients can present in a later stage without symptoms suggestive of earlier disease. Neuroborreliosis presents in early dissemination, with facial paralysis being the most common manifestation (11\% of cases, of which $30 \%-40 \%$ are bilateral) $[6,10]$. Other neurologic manifestations include lymphocytic meningitis, radiculopathy, and peripheral neuropathy. Diagnosis is supported by a positive serum antibody titer to Borrelia IgG. Doxycycline 100mg twice daily for 14 days is the treatment of choice and should be started immediately without waiting for serological confirmation. The treatment duration can be extended to up to 28 days in late disease (e.g. presence of carditis or arthritis). The prognosis is generally excellent with appropriate antibiotic therapy.

GBS is an acute immune-mediated polyradiculoneuropathy caused by cross-reaction to a preceding infection. Cardinal features include rapidly progressing symmetric muscle weakness accompanied by depressed deep tendon reflexes. GBS typically involves legs, arms, trunk, and face, with severity ranging from mild ambulation difficulty to nearly complete paralysis of all extremity, respiratory, bulbar, and facial muscles. Cranial nerves VII, IX, and X are most commonly affected in cranial neuropathy [1,2]. The facial nerve is involved in $27 \%-50 \%$ of cases and BFP is seen in $50 \%$ of these patients [2]. Although BFP can be the first and only symptom of GBS, it is a poor prognostic sign (occurs in up to $50 \%$ of fatal cases) as it represents high motor involvement and suggests possible respiratory failure $[7,16]$. The initial diagnosis is based on clinical presentation. Subsequent diagnostic certainty is supported by positive cerebrospinal fluid (elevated protein with normal white blood cell count) analysis and abnormal nerve conduction studies. Supportive care is the mainstay of treatment since up to $30 \%$ of cases develop respiratory failure requiring mechanical ventilation [17]. While $95 \%$ of cases demonstrate spontaneous remission and most patients show symptom improvement within four weeks, plasma exchange and intravenous immune globulin may be used within 10 days of symptom onset to accelerate recovery $[2,6,7]$.

Sarcoidosis is a multisystem granulomatous disorder of unknown etiology characterized by noncaseating granulomas. The pulmonary system is commonly affected (e.g. bilateral hilar adenopathy, pulmonary reticular opacities), although many patients have extrapulmonary sarcoid (e.g. eye and skin lesions) symptoms. Neurosarcoidosis usually manifests as cranial neuropathies, with the facial nerve being most commonly affected (unilateral palsy in $1 \%-3 \%$ and bilateral palsy in $0.1 \%-0.2 \%$ of patients) [10]. Other neurologic manifestations include neuroendocrine dysfunction, encephalopathy, and myelopathy. Diagnosis is supported by elevated serum angiotensin converting enzyme (ACE), tissue biopsy of affected organs, and enlarged lymph nodes on chest CT. Glucocorticoids for 4-6 weeks is used to reduce symptoms, although its effect on the natural course of neurosarcoidosis is unknown [2]. Patients with facial palsy are often treated with prednisone $0.5 \mathrm{mg} / \mathrm{kg} / \mathrm{day}$ for 2 weeks and improve over $2-4$ weeks [18].

BP is defined as acute facial palsy of unknown cause, with postulated mechanisms involving hereditary, vascular, infective, and inflammatory autoimmune factors [10]. It is often preceded by a viral infection (60\% of cases), with associated features including face or ear pain (50\%), facial numbness (40\%), dysgeusia (50\%), 
and tongue numbness (20\%) [1]. It is diagnosed clinically and treated with glucocorticoids (i.e. prednisone $60-80 \mathrm{mg} /$ day for seven days). Antivirals (e.g. valacyclovir 1000mg three times daily for 7-10 days) can be used in cases of severe facial palsy, especially in Ramsay-Hunt Syndrome. One side of the face often recovers immediately with the opposite side taking weeks to several months to fully recuperate $[8,10]$.

While BFP management varies drastically by etiology, the physician can consider early empiric corticosteroids given their efficacy in numerous differential diagnoses (e.g. pregnancy, sarcoidosis, systemic lupus erythematosus, neoplastic lesions, multiple sclerosis, temporal arteritis, BP), provided there are no contraindications. Antivirals or antibiotics (e.g. doxycycline) can be considered in those with a strong history of viral prodrome or bacterial infection (e.g. Lyme disease), respectively [9]. Although empiric management may be similar to that of unilateral facial palsy, patients must be followed closely to adapt therapy to new clinical, laboratory, and imaging findings. While the prognosis of BFP depends on the etiology, bilateral BP seems to recover as well as the unilateral form [1].

\section{Conclusions}

$\mathrm{BFP}$ is a rare presentation caused by a myriad of disparate conditions, many of which may be life-threatening and warrant immediate intervention. Common systemic diseases include Lyme disease, GBS, and sarcoidosis. It is prudent to have a diagnostic approach and consult Neurology urgently. Early empiric management with corticosteroids, antivirals, or antibiotics may be considered based on initial clinical and laboratory assessment.

\section{Additional Information \\ Disclosures}

Human subjects: Consent was obtained or waived by all participants in this study. Conflicts of interest: In compliance with the ICMJE uniform disclosure form, all authors declare the following: Payment/services info: All authors have declared that no financial support was received from any organization for the submitted work. Financial relationships: All authors have declared that they have no financial relationships at present or within the previous three years with any organizations that might have an interest in the submitted work. Other relationships: All authors have declared that there are no other relationships or activities that could appear to have influenced the submitted work.

\section{References}

1. Price T, Fife DG: Bilateral simultaneous facial nerve palsy. J Laryngol Otol. 2002, 116:46-8. 10.1258/0022215021910113

2. Jain V, Deshmukh A, Gollomp S: Bilateral facial paralysis: case presentation and discussion of differential diagnosis. J Gen Intern Med. 2006, 21:C7-10. 10.1111/j.1525-1497.2006.00466.x

3. Stahl N, Ferit T: Recurrent bilateral peripheral facial palsy . J Laryngol Otol. 1989, 103:117-9. 10.1017/s0022215100108199

4. Jung J, Park DC, Jung SY, Park MJ, Kim SH, Yeo SG: Bilateral facial palsy. Acta Otolaryngol. 2019, 139:934-8. 10.1080/00016489.2019.1651134

5. Sathirapanya P: Isolated and bilateral simultaneous facial palsy disclosing early human immunodeficiency virus infection. Singapore Med J. 2015, 56:e105-6. 10.11622/smedj.2015095

6. Gaudin RA, Jowett N, Banks CA, Knox CJ, Hadlock TA: Bilateral facial paralysis: a 13-year experience . Plast Reconstr Surg. 2016, 138:879-87. 10.1097/PRS.0000000000002599

7. Steenerson RL: Bilateral facial paralysis. Am J Otolaryngol. 1986, 7:99-103.

8. Rontal E, Sigel ME: Bilateral facial paralysis. Laryngoscope. 1972, 82:607-16. 10.1288/00005537-19720400000005

9. Kim YH, Choi IJ, Kim HM, Ban JH, Cho CH, Ahn JH: Bilateral simultaneous facial nerve palsy: clinical analysis in seven cases. Otol Neurotol. 2008, 29:397-400. 10.1097/mao.0b013e3181656998

10. Ozkara B, Budak F: Bilateral facial paralysis. Eurasian J Med. 2018, 2:41-4. 10.14744/ejmi.2017.97752

11. Hilsinger RL Jr, Adour KK, Doty HE: Idiopathic facial paralysis, pregnancy, and the menstrual cycle . Ann Otol Rhinol Laryngol. 1975, 84:433-42. 10.1177/000348947508400402

12. Vogell A, Boelig RC, Skora J, Baxter JK: Bilateral Bell palsy as a presenting sign of preeclampsia . Obstet Gynecol. 2014, 124:459-61. 10.1097/AOG.0000000000000221

13. Kovo M, Sagi Y, Lampl Y, Golan A: Simultaneous bilateral Bell's palsy during pregnancy. J Matern Fetal Neonatal Med. 2009, 22:1211-3. 10.3109/14767050903009255

14. Evangelista V, Gooding MS, Pereira L: Bell's palsy in pregnancy. Obstet Gynecol Surv. 2019, 74:674-8. 10.1097/OGX.0000000000000732

15. Hansen L, Sobol SM, Abelson TI: Otolaryngologic manifestations of pregnancy. J Fam Pract. 1986, 23:151-5.

16. Pothiawala S, Lateef F: Bilateral facial nerve palsy: a diagnostic dilemma . Case Rep Emerg Med. 2012, 2012:458371. 10.1155/2012/458371

17. Hughes RA, Wijdicks EF, Benson E, et al.: Supportive care for patients with Guillain-Barré syndrome. Arch Neurol. 2005, 62:1194-8. 10.1001/archneur.62.8.1194

18. Pawate S, Moses H, Sriram S: Presentations and outcomes of neurosarcoidosis: a study of 54 cases . QJM. 2009, 102:449-60. 10.1093/qjmed/hcp042 